\title{
Education
}

\section{Core competencies for emergency medicine clerkships: results of a Canadian consensus initiative}

\author{
Rick Penciner, MD*; Robert A. Woods, MD, MMEd ${ }^{\dagger}$; Jill McEwen, MD; Richard Lee, MD ${ }^{\ddagger}$; \\ Trevor Langhan, $\mathrm{MD}^{\|}$; Glen Bandiera, MD, MEd" from the Canadian Association of Emergency \\ Physicians Undergraduate Education Committee
}

\section{ABSTRACT}

Objectives: There is no consensus on what constitutes the core competencies for emergency medicine (EM) clerkship rotations in Canada. Existing EM curricula have been developed through informal consensus and often focus on EM content to be known at the end of training rather than what is an appropriate focus for a time-limited rotation in EM. We sought to define the core competencies for EM clerkship in Canada through consensus among an expert panel of Canadian EM educators.

Methods: We used a modified Delphi method and the CanMEDS 2005 Physician Competency Framework to develop a consensus among expert EM educators from across Canada.

Results: Thirty experts from nine different medical schools across Canada participated on the panel. The initial list consisted of 152 competencies organized in the seven domains of the CanMEDS 2005 Physician Competency Framework. After the second round of the Delphi process, the list of competencies was reduced to 62 (59\% reduction). A complete list of competencies is provided.

Conclusion: This study established a national consensus defining the core competencies for EM clerkship in Canada.

\section{RÉSUMÉ}

Objectif: II n'existe pas de consensus quant aux compétences de base à acquérir durant les stages cliniques en médecine d'urgence (MU) au Canada. Les programmes actuels en MU ont été élaborés à partir de consensus atteints de façon non structurée, et souvent l'accent est mis sur le contenu à connaître à la fin de la formation plutôt que sur un bagage approprié de connaissances à acquérir au cours d'un stage d'une durée limitée. Aussi cherchions-nous à définir les compétences de base à acquérir durant les stages en $\mathrm{MU}$ au Canada par l'atteinte d'un consensus au sein d'un groupe d'experts composé d'enseignants en MU au Canada.

Méthode: Nous avons eu recours à une version modifiée de la méthode Delphi et au Cadre de compétences CanMEDS pour les médecins de 2005 pour permettre l'atteinte d'un consensus parmi des enseignants en MU provenant de partout au Canada.

Résultats: Trente experts provenant de neuf écoles de médecine au Canada ont fait partie du groupe d'étude. La liste de départ comptait 152 compétences réparties dans les sept domaines du cadre CanMEDS 2005. À I'issue du deuxième tour du processus Delphi, la liste a été ramenée à 62 compétences (réduction de $59 \%$ ). Figure dans I'article la liste complète des compétences.

Conclusion: La présente étude a permis d'établir un consensus national quant aux compétences de base à acquérir durant les stages en MU au Canada.

Keywords: competencies, Delphi, education, emergency medicine, undergraduate

Undergraduate emergency medicine (EM) teaching in Canada is heterogeneous. There have been recommendations for national standards in this area. ${ }^{1}$ Recommendations for a fourth-year medical student EM curriculum have been published in the United States. ${ }^{2}$ The International Federation for Emergency Medicine recently described an international generic model curriculum for medical student education in EM. ${ }^{3}$ However, neither of these sets of recommendations were developed using validated methods defined

From the *Division of Emergency Medicine, Department of Family and Community Medicine, University of Toronto, Toronto, ON; †Department of Surgery, University of Saskatchewan, Saskatoon, SK; ‡Department of Emergency Medicine, University of British Columbia Vancouver, BC; $\S$ Department of Emergency Medicine, University of Alberta, Edmonton, AB; \|Division of Emergency Medicine, University of Calgary, Calgary, AB; \#Division of Emergency Medicine, Department of Medicine, University of Toronto, Toronto, ON.

Correspondence to: Dr. Rick Penciner, North York General Hospital, 4001 Leslie Street, 630N, Toronto, ON M2K 1E1; rick.penciner@utoronto.ca. This article has been peer reviewed. 
a priori. Furthermore, both focus on recommended core EM knowledge at the end of undergraduate training as opposed to what can reasonably be taught during a time-limited EM clerkship experience.

A core competency is defined as the essential knowledge, skill, or attitude needed to succeed in a given field. Defining learning objectives and core competencies for clinical clerkship has become a priority in medical education. ${ }^{4}$ The Liaison Committee on Medical Education (LCME) is the recognized accrediting authority for medical education programs leading to the medical doctorate degree for medical schools in the United States and Canada. The LCME requires medical school programs to specify the objectives of their educational program and ensure that all those responsible for teaching medical students are aware of those objectives. The objectives are to be stated in terms that allow assessment of student progress in developing the competencies that the profession and the public expect of a physician. ${ }^{5}$ There are already widely recognized definitions of the knowledge, skills, and attitudinal attributes appropriate for a physician, including those described in the Accreditation Council for Graduate Medical Education (ACGME) Outcome Project ${ }^{6}$ and the CanMEDS 2005 Physician Competency Framework. ${ }^{7}$ The Association of American Medical Colleges (AAMC) has defined the clinical skills curricula for undergraduate medical education. ${ }^{8}$ Implementing these recommendations requires educators to define from these general lists what is appropriate for every given educational experience (such as a course or clinical rotation). Most undergraduate and postgraduate medical education programs have already developed national core competencies for their respective overall programs. Although all programs are encouraged to design curricula to maximize local resources and constraints, a national reference core competency list for specific rotations can help ensure that nothing is missed, realistic priorities are set, and policy discussions are well informed.

The CanMEDS 2005 Physician Competency Framework was developed by the Royal College of Physicians and Surgeons of Canada as a competency framework or guide to the essential abilities physicians need for optimal patient outcomes. It consists of seven roles or thematic groups of competencies. Each role can be further broken down into smaller components for teaching, learning, and assessment. The seven roles are Medical Expert, Communicator, Collaborator, Manager, Health Advocate, Scholar, and Professional. ${ }^{7}$

Competency frameworks have been more readily applied to postgraduate medical education; however, changes to undergraduate curricula and evolving national accreditation standards have now shifted this to the undergraduate medical education realm. Using a competency-based framework to describe the activities and performance of the professional and working backward to build enabling competencies in the undergraduate curriculum may provide an authentic curriculum focused on the qualities and attributes required of a competent physician. Competency-based medical education does not specify particular learning strategies or formats but rather provides a clear description of intended outcomes. ${ }^{9}$

The Delphi process has been used extensively in social sciences and health-related research. The Delphi process is a group facilitation technique that seeks to obtain consensus on the opinions of experts through a series of structured questionnaires (rounds) in an iterative multistage process designed to transform opinion into group consensus. ${ }^{10}$ It has been demonstrated that a modified Delphi process can result in a strong consensus around a realistic number of core competencies for EM clerkships. ${ }^{11}$

In January 2009, a working group of the Canadian Association of Emergency Physicians (CAEP) Undergraduate Education Committee was established to lead a project on the development of EM clerkship core competencies. The purpose of this project was to define the core competencies for EM clerkship in Canada as determined by an expert panel of Canadian EM educators.

\section{METHODS}

Using a modified Delphi process, we developed a consensus among a panel of expert EM undergraduate educators from across Canada using the CanMEDS 2005 Physician Competency Framework. ${ }^{7}$

\section{Questionnaire development}

A convenience sample of experts in EM undergraduate education (six project investigators) developed a comprehensive list of competencies for the EM clerkship. This list was developed by consulting multiple sources, including a review of the published literature 
and the grey literature (Internet) for existing EM curriculum and course objectives, and reviewing the course curricula of nine Canadian medical school EM clerkships (documents that were readily accessible through correspondence and websites) until saturation was reached. The list of competencies was organized into the domains described in the CanMEDS 2005 Physician Competency Framework ${ }^{7}$ by consensus of two study investigators (R.P., G.B.). This comprehensive list underwent a series of edits and additions with a view to inclusivity until there was consensus among the expert panel.

A questionnaire was developed using a Web-based survey tool (SurveyMonkey, Surveymonkey.com, Palo Alto, CA). Each item consisted of a description of the competency followed by a 7-point Likert scale indicating the strength of agreement on whether the competency should be included in a 4-week EM clerkship rotation (distinct from what students should know about EM on graduation). Detailed instructions for panel members on what to consider when rating each competency were developed. In addition, panel members were given the opportunity to add any additional competencies at their discretion. The questionnaire was piloted with nine EM educators. Final edits were made to the questionnaire based on feedback received.

\section{Round 1}

A larger representative panel of expert EM undergraduate educators in Canada was identified. The EM undergraduate coordinator/director at each Englishspeaking medical school in Canada $(n=13)$ was invited by e-mail to participate. Using a "snowball" technique, ${ }^{12}$ we asked each EM undergraduate coordinator/director to identify four additional "experts" at their university and to provide the principal investigator (R.P.) with their names and e-mail addresses. An expert was defined as an "emergency medicine physician with expertise and/or interest in emergency medicine undergraduate education." The principal investigator contacted potential participants by e-mail to ensure interest and agreement to participate in the project. Reminder invitations were sent at weekly intervals twice. Participation in the panel was voluntary. The process was conducted in a quasianonymous manner. Respondents' identity was known to the principal investigator only to allow for reminders and provision of feedback in subsequent rounds. The participants' judgments and opinions remained strictly anonymous to members of the expert panel. On March 4, 2010, an e-mail was sent to each member of the panel with a link to an online questionnaire. Reminder e-mails were sent at weekly intervals twice. Each participant was asked to rate each competency on a 7point Likert scale as described above.

\section{Round 2}

Competencies rated as 6 or 7 were categorized as "must include," 4 or 5 as "for consideration" and 1, 2, or 3 as "not include." The principal investigator ranked the competencies from highest percent to lowest percent of "must include" responses within each CanMEDS competency domain. Competencies rated "not include" by $75 \%$ or more of the respondents were eliminated from the list. Panel members were subsequently invited by e-mail 22 days after the first questionnaire to complete a second online questionnaire. Each panel member was asked to rate each competency using a scale of only "must include" or "not include." The panel's aggregate responses for each competency from round 1 were noted beside each competency as a percentage of "not include," "for consideration," and "must include." Reminder e-mails were sent at weekly intervals twice.

\section{Evaluation methods}

Using descriptive statistics, we rank-ordered the competencies based on the percent response of "must include." Inclusion criteria for the final list were those competencies for which $75 \%$ or more respondents provided a response of "must include."

\section{External review}

On completion of data collection, the project was reviewed by four external reviewers. The reviewers included three nationally recognized EM educators/ researchers (who did not participate in the study) and one nationally recognized family medicine undergraduate educator/researcher. Reviewers were asked to provide a brief narrative commenting whether the project results were valid, useful, and applicable to EM clerkship and whether the methodology was appropriate to inform competency and curriculum development. 
The study was approved by the University of Toronto Health Sciences Research Ethics Board.

\section{RESULTS}

Nine clerkship directors responded to the initial invitation, providing the names of 33 potential participants (including the clerkship directors). Of these potential participants, 30 consented to participate on the expert panel. One panel member did not respond to the second questionnaire. There was representation from 9 of the 17 medical schools in Canada (range $=2-5$ participants per school), with six different provinces represented.

The expert panel $(n=30)$ was diverse in terms of education background and expertise (Table 1). The initial list of competencies consisted of 152 competencies organized in the seven domains of the CanMEDS framework. After round 2 of the Delphi process, the list

\begin{tabular}{lc}
\hline Table 1. Profile of expert panel $(\boldsymbol{n}=\mathbf{3 0})$ & \\
\hline Characteristic & $n(\%)$ \\
\hline Years in practice & \\
$\quad<5$ & $5(17)$ \\
$5-10$ & $8(27)$ \\
$10-15$ & $9(30)$ \\
$>15$ & $8(26)$ \\
Certification & \\
CCFP (EM) & $18(60)$ \\
FRCP (EM) & $16(53)$ \\
$\quad$ Dual certification & $4(13)$ \\
University rank & $6(20)$ \\
Lecturer & $12(40)$ \\
Assistant professor & $11(37)$ \\
Associate professor & $1(3)$ \\
Professor & \\
Practice setting & $26(87)$ \\
$\quad$ Academic health science centre & $3(10)$ \\
Community teaching hospital & $1(3)$ \\
Community hospital & \\
Practice mix & $15(50)$ \\
Almost exclusive adult patients & $15(50)$ \\
Mix of both adult and pediatric patients & \\
Involvement in EM clerkship teaching in past 5 yr & \\
Clinical teaching (e.g., teaching during shifts) & $29(97)$ \\
Nonclinical teaching (e.g., seminars) & $27(90)$ \\
Workshop/seminar coordination/administration & $19(63)$ \\
Curriculum development & $16(53)$ \\
Course committee & $16(53)$ \\
Course director & $15(50)$ \\
\hline
\end{tabular}

of competencies was reduced from 152 to 62 competencies, a $59 \%$ reduction (Table 2, Table 3, Table 4, Table 5, Table 6, Table 7, Table 8, Table 9, Table 10 , and Table 11).

\section{DISCUSSION}

The Delphi process has been used extensively in social science and health-related research. The process allows researchers to seek out information that may generate a consensus on the part of the respondent group. It is increasingly being used in health professional education research, including curriculum and competency. ${ }^{13-21}$ We describe in a previous publication the rationale development for the use of a Delphi process to establish consensus on EM clerkship competencies and the effectiveness of this approach. ${ }^{11}$ The methodology described in this study, as previously published, was seen by external reviewers to have face validity, applicable to EM clerkships in Canada and appropriate to inform competency and curriculum development.

The Delphi process is an effective method of collecting opinion and determining consensus. However, a universally agreed proportion does not exist as the level used depends on the sample numbers, aim of the research, and resources. The reported level of consensus in the literature ranges from 51 to $80 \% .{ }^{10}$ The level of consensus that we sought was $75 \%$ of respondents supporting the contention that the competency "must be included." We chose a high level of consensus to ensure that a manageable, core list of competencies was developed that a medical student could encounter during a time-limited EM clerkship rotation. However, we have disseminated all 152 competencies along with the groups' collective rating "whether the competency must be included." This will allow flexibility for educators and curriculum developers to move the threshold for inclusion up or down.

There has been an active debate in the literature on the validity of the Delphi process. ${ }^{22}$ The validity of our study was enhanced by ensuring that a representative panel of experts from across Canada was recruited. Our experts represented every province with a medical school with the exception of two. The experts' profile was diverse in terms of educational background. Our high response rates and use of successive rounds also increased the validity of the results.

We chose to use the CanMEDS Framework because it is the framework used by all Canadian residency programs, it is increasingly being used to inform 
Table 2. Medical Expert (general) competencies

Competency (above double line is $75 \%$ consensus)

No. of experts

who chose "must

include" (\%)

Demonstrate the ability to rapidly recognize and initiate basic management of acute life- or limb-threatening illness or

$29(100)$

injury

Describe a basic differential diagnosis including the significant worst-case diagnosis for every patient assessed

$29(100)$

Demonstrate a basic systematic, prioritized approach to resuscitation and stabilization of emergencies

$29(100)$

Demonstrate a basic ability to distinguish seriously ill or injured patients from those with minor conditions

$28(97)$

Demonstrate a focused history and physical examination

$28(97)$

Distinguish which conditions are life-threatening or emergent from those that are less urgent

$28(97)$

Demonstrate the ability to evaluate and initiate treatment of the undifferentiated patient

27 (93)

Describe the concept of triage and prioritization of care

27 (93)

Recognize that certain groups of patients require a high index of suspicion for serious illness (e.g.,

immunocompromised, chronic renal failure, transplant, extremes of age, intoxicated, and diabetes)

27 (93)

Monitor the response to therapeutic interventions

$20(69)$

Describe the risks and benefits of investigations and treatments used in the ED for the common presenting problems

17 (59)

Recognize and initiate management of a presentation related to domestic violence

$17(59)$

Demonstrate an understanding of the concept of triage and prioritization of care in management of multiple patients

simultaneously

List which areas in the ED are most appropriate for various triage categories and types of patients

$15(52)$

Describe the 5 levels of the Canadian Triage and Acuity Scale

$14(50)$

Perform a rapid triage assessment

$11(38)$

$8(28)$

$\mathrm{ED}=$ emergency department.

undergraduate medical education, and it is familiar to most medical educators in Canada. We previously demonstrated that the CanMEDS Framework is a valid and practical framework to structure competencies and curriculum at the undergraduate level. ${ }^{11}$

The number of competencies for the Medical Expert role (43) was significantly more than all the other roles combined. ${ }^{19}$ This reflects the traditional teaching paradigm of all medical schools and the fact that medical knowledge and skills are still at the core of the curriculum for medical students. More programs are being developed for medical schools that reflect how to incorporate the non-Medical Expert roles into the curriculum. ${ }^{23,24}$ Of note, the expert panel did not include any competencies for the Manager role in the final list. This may reflect the fact that they believe the role is not appropriate for students in undergraduate education. It may also reflect an exercise of priorities in what should be included in a time-limited EM clerkship.

Distilling a large list of competencies related to EM into a core group that can reasonably be achieved in a time-limited clerkship (and, in doing so, recognizing that some competencies can be addressed elsewhere in the MD program) can be a challenge for individual program leaders. In designing local clinical experiences (such as clerkships), rotation coordinators must resist the urge to be overly inclusive with their list of rotationspecific objectives and competencies. Although program leaders may feel that an inclusive list of competencies "defines" their specialty, such long lists of educational objectives are infrequently completely met. Goals and objectives set the expectations for the rotation for both what is to be learned and what is to be taught, therefore implying responsibility on both teacher and learner. It is in everybody's best interest that these objectives be feasible given the constraints of the rotation. The educational standards set by the LCME describe that this should be the case. The LCME standards also require that "the faculty must monitor medical students' experiences and modify them as necessary to ensure that the objectives of the medical education program are met. ${ }^{5}$ Therefore, objectives that are too high reaching may be seen as a deficiency with respect to accreditation standards. A national effort focused on rotation-based objectives promises to help in this regard.

There is no systematically derived curriculum that defines the basic minimum curricular expectations for EM undergraduate rotations in Canada. Recently, the International Federation for Emergency Medicine 
Table 3. Medical Expert (presenting problem) competencies

\begin{tabular}{|c|c|}
\hline $\begin{array}{l}\text { Competency (above double line is } 75 \% \\
\text { consensus) }\end{array}$ & $\begin{array}{l}\text { No. of } \\
\text { experts who } \\
\text { chose "must } \\
\text { include" (\%) }\end{array}$ \\
\hline \multicolumn{2}{|l|}{$\begin{array}{l}\text { Demonstrate an approach to patients presenting } \\
\text { to the ED with the following problems (including } \\
\text { basic differential diagnosis, initial investigations, } \\
\text { and initial treatments): }\end{array}$} \\
\hline Chest pain & $29(100)$ \\
\hline Shortness of breath & $29(100)$ \\
\hline Altered level of consciousness & $29(100)$ \\
\hline Anaphylaxis/severe allergic reaction & $28(97)$ \\
\hline Abdominal pain & $28(97)$ \\
\hline Loss of consciousness (syncope) & $28(97)$ \\
\hline Shock & $28(97)$ \\
\hline Seizure & $27(93)$ \\
\hline Cardiorespiratory arrest & $27(93)$ \\
\hline Headache & $27(93)$ \\
\hline $\begin{array}{l}\text { Minor trauma (including fracture/dislocation/ } \\
\text { sprain) }\end{array}$ & $27(93)$ \\
\hline $\begin{array}{l}\text { Abnormal behaviour (e.g., psychosis, delirium, } \\
\text { intoxication, violence) }\end{array}$ & $25(86)$ \\
\hline Head injury—minor & $25(86)$ \\
\hline Fever & $23(79)$ \\
\hline Dizziness/vertigo & $23(79)$ \\
\hline Cardiac dysrhythmias & $22(76)$ \\
\hline Vaginal bleeding-pregnant & $22(76)$ \\
\hline Poisoning & $21(72)$ \\
\hline Gastrointestinal bleeding & $21(72)$ \\
\hline Eye pain (including red eye) & $21(72)$ \\
\hline Vomiting & $20(69)$ \\
\hline Back pain & $20(69)$ \\
\hline Urinary symptoms (e.g., dysuria, hematuria) & $20(69)$ \\
\hline Major trauma & $19(68)$ \\
\hline Intoxication/withdrawal & $19(66)$ \\
\hline Burn-minor & $19(66)$ \\
\hline Depression/suicidal & $17(59)$ \\
\hline Epistaxis & $17(59)$ \\
\hline Diarrhea & $17(59)$ \\
\hline Burn-major & $17(59)$ \\
\hline Weakness & $16(55)$ \\
\hline Pelvic pain & $14(48)$ \\
\hline Bites (animal/insects) & $14(48)$ \\
\hline Ear pain & $13(45)$ \\
\hline Heat injury & $12(41)$ \\
\hline Vaginal bleeding-nonpregnant & $11(38)$ \\
\hline Vision change & $11(38)$ \\
\hline Cold injury & $11(38)$ \\
\hline Urinary retention & $9(31)$ \\
\hline Rash & $7(24)$ \\
\hline Foreign body (cavitary, ENT) & $6(21)$ \\
\hline
\end{tabular}

Table 4. Medical Expert (technical skills performed) competencies

No. of experts who

Competency (above double line is $75 \%$ chose "must consensus) include" (\%)

Demonstrate competency in performing the

following procedural skills (including indications, contraindications):

Suturing simple laceration $29(100)$

Perform wound cleansing and simple dressing $29(100)$

Local anesthetic infiltration 29 (100)

Perform basic airway maneuvers (head tilt, chin 27

lift, jaw thrust, oral/nasal airway insertion, bag-

mask ventilation)

Place patient on oxygen (nasal prongs,

24 (83)

nonrebreather mask)

Apply an extremity plaster splint $23(79)$

Place patient on pulse oximeter $22(76)$

CPR (chest compressions)

$22(76)$

Digital nerve block

$21(72)$

Defibrillation/cardioversion

$19(66)$

Place patient on cardiac monitor $19(66)$

Apply an extremity plaster cast $19(66)$

Slit-lamp examination 17 (59)

Urinalysis—dipstick 15 (52)

Incision and drainage of abscess 15 (52)

Peripheral intravenous line insertion $14(48)$

Basic dislocation reduction 14 (48)

Basic fracture reduction $13(45)$

Obtain electrocardiograms 12 (41)

Venipuncture 11 (39)

Lumbar puncture 10 (35)

Arterial blood gases 10 (35)

Nasal packing $10(35)$

Nasogastric tube placement 9 (31)

Procedural sedation 9 (31)

Perform advanced airway manoeuvres 8 (28)

(orotracheal intubation using laryngoscope)

External pacing $7(24)$

Foley catheter insertion 6 (21)

Foreign body removal 6 (21)

Nasal cautery 6 (21)

Urinalysis-microscopy 5 (17)

Needle thoracostomy 5 (17)

Portable spirometry 5 (17)

Corneal foreign body removal 4 (14)

Tonometry 4 (14)

$\mathrm{CPR}=$ cardiopulmonary resuscitation 


\section{Table 5. Medical Expert (technical skills interpretation) competencies}

Competency (above double line is $75 \%$ consensus)

No. of experts who chose "must include" (\%)

Demonstrate competency in performing the following interpretive skills:

12-lead ECG-myocardial infarction $\quad 29$ (100)

12-lead ECG—rhythm analysis $\quad 28$ (97)

Cardiac monitor (rhythm analysis) $\quad 27$ (93)

Chest radiograph interpretation 26 (90)

Pulse oximetry $\quad 25$ (86)

Extremity radiograph interpretation $\quad 25$ (86)

C-spine radiograph interpretation $\quad 23$ (79)

Urinalysis—dipstick and microscopy 22 (76)

Arterial blood gases 18 (62)

Abdominal radiograph interpretation $\quad 17$ (59)

CSF analysis 14 (48)

Venous blood gases 12 (41)

$\begin{array}{ll}\text { Portable spirometry } & 6 \text { (21) }\end{array}$

$\mathrm{CSF}=$ cerebrospinal fluid; $\mathrm{ECG}=$ electrocardiogram.

Table 6. Communicator competencies

$\begin{array}{lc}\text { Competency (above double line is } 75 \% \text { consensus) } & \begin{array}{c}\text { No. of experts who } \\ \text { chose "must } \\ \text { include" (\%) }\end{array} \\ \begin{array}{lc}\text { Demonstrate the ability to present a patient case in a clear, concise, and complete } \\ \text { manner }\end{array} & 28 \text { (97) } \\ \text { Communicate effectively and empathetically with patients and their families } & 28 \text { (97) } \\ \begin{array}{l}\text { Demonstrate thorough, clear, and concise documentation and charting } \\ \text { Provide clear discharge instructions for patients and ensure appropriate follow-up }\end{array} & 27 \text { (93) } \\ \text { care. } & 14 \text { (48) } \\ \text { Demonstrate the ability to counsel and educate patients and families in the ED } & \end{array}$

Table 7. Collaborator competencies

Competency (above double line is $75 \%$ consensus)

Establish and maintain effective working relationships with colleagues and other health care professionals

Describe the role of other health professionals in the management of the patient in the ED.

Respect the role of the patient's primary care physician by soliciting input in the assessment, in the development of the care plan, and in follow-up

Describe when, why, and how other medical specialties should be consulted

Discuss the roles of the various providers of prehospital care and the role of the emergency physician in prehospital care

Demonstrate a basic knowledge of community resources available to the ED

$\mathrm{ED}=$ emergency department
No. of experts who chose "must include" (\%)

$29(100)$

$26(90)$

$18(62)$

$17(61)$

$13(45)$

$10(35)$ 
Table 8. Manager competencies

Competency (above double line is $75 \%$ consensus)

No. of experts

who chose "must include" (\%)

Demonstrate a basic understanding of the way the ED works (basic functioning, referrals, role of other health

$21(72)$

professionals)

Describe the difference between ED patient care and the treatment in other health care settings (e.g., inpatients, family practice)

Discuss the role of the ED in the health care system and how it relates to other hospital and community health services

$16(55)$

Demonstrate appropriate and cost-effective use of investigations and treatments

Describe some factors contributing to resource issues in the ED

$10(35)$

Demonstrate basic skills in time management, establishing priorities, and simultaneously managing multiple patients

Develop organizational skills and efficiency in managing patients and maintaining patient flow

Describe the basic principles of disaster planning

$E D=$ emergency department.

described a model curriculum for medical student education in EM. ${ }^{3}$ This curriculum was developed through informal consensus and involves a long list of curriculum content that would be hard to deliver solely in an EM clerkship. Instead, it was conceptualized as terminal objectives at completion of medical school. In the United States, a task force representing six major EM organizations developed a national fourth-year medical student EM curriculum guide. There are no clear methods describing how this curriculum was developed. Furthermore, our results define core competencies rather than a core curriculum.

Recognizing this practical curriculum planning need, we describe an expert-derived consensus on a set of competencies that can be achieved in a timelimited EM clerkship in Canada. Our model takes the form of competencies and objectives organized in a framework familiar to most Canadian and many international medical educators. Individual rotation coordinators can adapt this defined, limited list to reflect what they can offer consistently to all trainees. The list of competencies provided is certainly not meant to be prescriptive. Practice patterns vary by institution, and different clinical rotations will offer different encounters depending on the variety and scope of other rotations available to students over their entire clinical training. Items near the top of the consensus list for each category may be covered well by other rotations, and, conversely, items low on the consensus may only be covered in the ED.

There are a number of limitations to this study. The Delphi process itself has limitations, including

Table 9. Advocate competencies

Competency (above double line is $75 \%$ consensus)

No. of experts who chose "must include" (\%)

Demonstrate effective advocacy for patient comfort (including pain management, basic needs)

$29(100)$

Demonstrate an awareness of the underlying psychosocial and socioeconomic problems that may precipitate an $22(76)$

ED visit

Demonstrate an understanding of the principles of informed consent, right of competent patients to refuse

$20(71)$

treatment, and implied consent

Identify opportunities to discuss injury prevention with patients (e.g., seat belts, bike helmets)

$20(69)$

Recognize the importance of screening for domestic violence

$18(62)$

Demonstrate a basic understanding of legal and ethical issues surrounding emergency care

$16(55)$

Describe the scenarios in which mandatory reporting of authorities is required by law

$14(48)$

Identify opportunities to provide health promotion to patients (e.g., smoking cessation, weight loss)

$14(50)$

Discuss the indications and procedures for certification and involuntary status under the Mental Health Act

$13(45)$

Demonstrate effective advocacy for access to resources for individual patients (respecting the needs of the

$11(38)$

individual and those of the population)

$E D=$ emergency department. 
Table 10. Scholar competencies

Competency (above double line is $75 \%$ consensus)

No. of experts who

chose "must include" $(\%)$

Demonstrate an ability to access various educational resources available to enhance patient care

$23(79)$

Demonstrate a basic ability to self-guide professional development, including identifying and addressing learning needs

Demonstrate an understanding of the concepts of evidence-based medicine and best practice guidelines and how

they relate to patient care in the ED

Describe some of the many unique learning and teaching opportunities available in emergency medicine

$22(76)$

Demonstrate an ability to critically appraise the literature relevant to ED care

$18(62)$

$13(45)$

$5(17)$

$\mathrm{ED}=$ emergency department.

concerns regarding the lack of reliability. ${ }^{10}$ Inherent in the anonymity of the process is a danger of the lack of accountability of the opinions expressed. Our expert panel had no representation from two provinces that have medical schools and did not include representation from French-language medical schools in Canada. The panel included only four physicians from community hospitals (teaching and nonteaching). This limited representation on the panel is reflective of the fact that most EM clerkships in Canada presently occur in academic health science centres. The panel may have been more robust with inclusion of other medical educators, students (or recent graduates), and possibly patients. Our study used the CanMEDS 2005 Competency Framework ${ }^{7}$ to organize the competencies. Although this framework is increasingly informing undergraduate education, it has not been adopted by all medical schools in Canada.

\section{CONCLUSIONS}

This study established a national consensus defining the core competencies for EM clerkship in Canada.

Acknowledgements: We are grateful to the external reviewers: Jonathan Sherbino, McMaster University; Farhan Banji, McGill University; Eddy Lang, University of Calgary; and Risa Freeman, University of Toronto. We also gratefully acknowledge the members of the expert panel, including Simon Field, Connie LeBlanc, John Ross, Dalhousie University; Danielle Blouin, Jaelyn Caudle, Jim Landine, Queen's University; Randy Cunningham, Ryan Oland, Curtis Rabuka, Andrew Stagg, University of Alberta; Nancy Austin, Mike Mostrenko, Patrick Rowe, University of British Columbia; Laurie-Ann Baker, David Lendrum, University of Calgary; Albert Buchel, Zoe Oliver, University of Manitoba; Jason Frank, Brian Weitzman, University of Ottawa; Nadim Lalani, Patrick Ling, University of Saskatchewan; Shirley Lee, Rahim Valani, Stella Yiu, University of Toronto.

Competing interests: None declared.

Table 11. Professional competencies

Competency (above double line is $75 \%$ consensus)

No. of experts who chose "must include" (\%)

Recognize and accept one's limitations and know when to ask for help $29(100)$ Be reliable and responsible in fulfilling obligations $29(100)$ Take the appropriate measures to protect oneself from illness and injury $28(97)$ Demonstrate honesty and integrity in patient care

Demonstrate sensitivity to cultural issues (e.g., age, sex, culture, disability)

Maintain a professional appearance

Demonstrate compassion and nonjudgmental approach to all patients

Protect information provided by or about patients, keeping it confidential, and divulge it only with the patient's permission except when otherwise required by law

Demonstrate ethical decision making

27 (93)

27 (93)

27 (93)

27 (93)

25 (89)

$23(82)$

Recognize situations where common medical errors may occur in the ED

20 (69)

$E D=$ emergency department. 


\section{REFERENCES}

1. Frank JR, Penciner R, Upadhye S, et al. State of the nation: a profile of Canadian emergency medicine clerkships 2007. CFEM 2008;10:266.

2. Manthey DE, Coates WC, Ander DS, et al. Report of the task force on national fourth year medical student emergency medicine curriculum guide. Ann Emerg Med 2006;47:E1-7, doi:10.1016/j.annemergmed.2005.09.002.

3. Hobgood C, Anantharaman V, Bandiera G, et al. International Federation for Emergency Medicine model curriculum for medical student education in emergency medicine. CFEM 2009;11:349-54.

4. Burke MJ, Brodkey AC. Trends in undergraduate medical education clinical clerkship learning objectives. Acad Psychiatry 2006;30:158-65, doi:10.1176/appi.ap.30.2.158.

5. Liaison Committee on Medical Education. LCME accreditation standards - educational program for the MD degree: educational objectives. Available at: http://www.lcme.org/functionslist. htm\#educational program (accessed August 9, 2010).

6. Accreditation Council of Graduate Medical Education. ACGME Outcome Project 2010. Available at: http://www. acgme.org/outcome (accessed August 16, 2010).

7. Frank JR, editor. The CanMEDS 2005 physician competency framework: better physicians, better care. Ottawa: The Royal College of Physicians and Surgeons of Canada; 2005. Available at: http://rcpsc.medical.org/canmeds/CanMEDS 2005/CanMEDS2005_e.pdf (accessed August 9, 2010).

8. Association of American Medical Colleges. Recommendations for clinical skills curricula for undergraduate medical education 2005. Available at: https://services.aamc.org/Publications/ showFile.cfm? file = version56.pdf\&prd_id $=141 \&$ prv_id $=165$ \&pdf_id=56 (accessed August 9, 2010).

9. Harris P, Snell L, Talbot M, Harden RM. Competencybased medical education: implications for undergraduate programs. Med Teach 2010;32:646-50, doi:10.3109/01421 59X.2010.500703.

10. Hasson F, Keeney S, McKenna H. Research guidelines for the Delphi survey technique. 7 Adv Nurs 2000;32:1008-15.

11. Penciner R, Langhan T, Lee R, et al. Using a Delphi process to establish consensus on emergency medicine clerkship competencies. Med Teach 2011;33:e333-9, doi:10.3109/ 0142159X.2011.575903.

12. Valente TW, Pumpuang P. Identifying opinion leaders to promote behaviour change. Health Educ Behav 2007;34:88196, doi:10.1177/1090198106297855.
13. Barton AJ, Armstrong G, Preheim G, et al. A national Delphi to determine developmental progression of quality and safety competencies in nursing education. Nurs Outlook 2009;57:313-22, doi:10.1016/j.outlook.2009.08.003.

14. Fried H, Leao AT. Using Delphi technique in a consensual curriculum for peridontics. 7 Dent Educ 2007;71:1441-6.

15. Walley $\mathrm{T}$, Webb DJ. Developing a core curriculum in clinical pharmacology and therapeutics: a Delphi study. $\mathrm{Br} 7$ Clin Pharmacol 1997;44:167-70, doi:10.1046/j.1365-2125. 1997.00669.x.

16. Esmaily HM, Savage C, Vahidi R, et al. Identifying outcome-based indicators and developing a curriculum for a continuing medical education programme on rational prescribing using a modified Delphi process. BMC Med Educ 2008;8:33, doi:10.1186/1472-6920-8-33.

17. Flynn L, Verma S. Fundamental components of a curriculum for residents in health advocacy. Med Teach 2008;30: e178-83, doi:10.1080/01421590802139757.

18. Paes P, Wee B. A Delphi study to develop the Association for Palliative Medicine consensus syllabus for undergraduate palliative medicine in Great Britain and Ireland. Palliat Med 2008;22:360-4, doi:10.1177/0269216308090769.

19. Clayton R, Perera R, Burge S. Defining the dermatological content of the undergraduate medical curriculum: a modified Delphi study. Br 7 Dermatol 2006;155:137-44, doi:10.1111/ j.1365-2133.2006.07190.x.

20. Perkins GD, Barrett H, Bullock I, et al. The Acute Care Undergraduate Teaching (ACUTE) Initiative: consensus development of core competencies in acute care for undergraduates in the United Kingdom. Intensive Care Med 2005; 31:1627-33, doi:10.1007/s00134-005-2837-4.

21. Hueston WJ, Koopman RJ, Chessman AW. A suggested fourth-year curriculum for medical students planning on entering family medicine. Fam Med 2004;36:118-22.

22. Jones J, Hunter D. Consensus methods for medical and health services research. $B r$ Med $\mathcal{F}$ 1995;311:376-80, doi: 10.1136/bmj.311.7001.376.

23. Laidlaw A, Hart J. Communication skills: an essential component of medical curricula. Part I: Assessment of clinical communication: AMEE Guide No 51. Med Teach 2011;33:6-8, doi:10.3109/0142159X.2011.531170.

24. O'Sullivan $\mathrm{H}$, van Mook W, Fewtrell R, et al. Integrating professionalism into the curriculum. Med Teach 2012;34:1557, doi:10.3109/0142159X.2011.595600. 